\title{
Watching television films and time management skill of students as predictors of achievement motivation of primary school students: the case of woldia town
}

\author{
Kifle Kassaw Mulatu ${ }^{*}$ \\ Woldia College of Teachers Education, Ethiopia \\ ${ }^{*}$ Corresponding author, ఏe-mail: negedekifle@yahoo.com
}

\begin{abstract}
The study attempted to examine students extent of Watching TV films and drama. The study followed mainly a correlation design and was conducted on 306 students drawn from three randomly selected primary schools in Woldia town,. Data on respondents' were collected using close ended questionnaires. Pearson correlation was used to see the relation between variables, the result showed that the independent variables do have a significant relationship with the dependent variable except in low TV films and drama viewers. Extent of Watching TV films and drama of students in the study area were $23.2 \%$ Heavy TV films and drama Viewers/above 3.5 hrs per day/,33.6 \% Medium TV films and drama Viewers /between 2.5 up to $3.5 \mathrm{hrs}$ per day and $43.14 \%$ low TV films Viewer/below $2.5 \mathrm{hrs}$ per day/. Results of the multiple linear regression revealed that Watching TV films and Time management skill of students interaction taken together explained $18.6 \%, 11.5 \%$ and $3.5 \%$ in heavy ,medium and low TV films and dramas Viewers of the variance in achievement Motivation. Thus, based on the findings it can be concluded that Watching TV films and drama and time management skills of students are important precursors of achievement Motivation. Following the conclusion several recommendations were forwarded
\end{abstract}

Keywords: Watching film, time management skill, achievement.

How to Cite: Mulatu, K. (2020). Watching television films and time management skill of students as predictors of achievement motivation of primary school students: the case of Woldia Town. COUNSEDU: The International Journal of Counseling and Education, 5(3). 136-145 DOI: http://dx.doi.org/ $10.23916 / 0020200527220$

This is an open access article distributed under the Creative Commons Attribution License, which permits unrestricted use, distribution, and reproduction in any medium, provided the original work is properly cited. (C2020 by author.

\section{Introduction}

Television has been accused of negatively impacting academic achievement in various ways. Wright and Colleagues (2001) for example combine high exposure to general audience television with low language rates. These low-language ratings are due more to the quality of the show than to the time spent watching TV programmes. Omojuwa et al. (2009) argued that programs for the general public are not intended for teaching purposes, but for entertainment purposes. These include soaps, movies, entertainment, documentaries, musicals, sports (football games), television reality shows, comedy talk shows, cartoons etc. Similarly, television was accused of displacing time for reading and thus imminent intellectual abilities (Winn, 2002). The idea is that when television and reading are fighting for more time and attention, television is always gaining predominance as more attractive. This could be accurate in other cases. However, the insufficiency and insecurity of electricity supply throughout Nigeria limits the time when television is available and accessible. Hence one would presume that, given television, reading, which is less energy-reliant, would maintain primacy. But this is not the case because there are other things that could prevent students from reading their books, such as playing games, in viewing centres. 
Watch the European Premier League, Champions League, Spanish Laliga, especially on weekends when students are meant to revisit and read their books and solve their home assignment. According to Taiwo (2004), although television sets are used to entertain, educate and raise awareness of ideas that might never be found in other areas, it has now become a threat to children's well-being, especially in terms of their behavior and academic achievement. Popoola (2008) argued that television had a significant impact on student performance in the mathematics test in his study "The Effect of TV and Radio Distractions on Graduate Student Mathematics Test Performance." So television was seen as a diversion when studying in this case. During learning distraction via television has become a common daily occurrence among secondary school students across the country. Many researchers have focused on the influence of distraction on student learning / academic motivation, while studies have shown some negative effects of distraction on learning and academic achievement.

Distraction can affect learning at the general level because, according to the theory of capacity, attention can be divided when the brain is exposed to two separate tasks that require attention (Tina \& Melinda, 2007). However, one of the two tasks of either reading or watching television will be reduced when that happens. Because television is seen as a diversion, especially when it comes to concentrating on their academics, it is important to find out what impact television and movie programs have on student reading and academic achievement.

The Canadian Pediatric Society (2003) argued that the less time they spend with their families the more children spend watching TV. While television can separate children, it is also possible to reverse the causal course. For fun and companionship, the lonely kids turn to TV. Bickham (2007) also noted that children marginalized by their peers are using television to ease the burden of their lives and satisfy their social needs. Conversely, emotionally integrated children spend less time watching television. Research also suggests that playing video games at home and watching television have a negative impact on academic achievement for children. If kids watch video from home, they usually don't talk about school activities or do homework. In a Sharif (2006) study of 4,500, the amount and time of children playing video games influences any negative effects in relation to their academic progress.

A survey of Malaysian youth found that they spend about 32.6 hours a day watching TV, surfing the Internet, listening to radio and reading magazines (Raj, 2012). These tasks can exceed 24 hours a day, as technology enables us to do multitasking. You can talk on the phone, watch TV, and update your Facebook account while listening to the music. However, research shows that more than $30 \%$ or nearly 11 hours of 32.6 hours are spent on media-related activities such as Internet surfing ( 3.3 hours), watching TV (2.5 hours) and using phones (1.3 hours).

\section{Statement of the problem}

The Media Awareness Network (retrieved 19/5/09) points out those children who watch television perform better moderately than those who spend much time watching it. Armstrong, Boirsky, \& Mares (1991) research revealsthat watching T.V. overly interferes with the retention skills of children when carrying out homework. National development via education is planned. If the students do not focus on the classroom, read and study by themselves or review their lessons,

Therefore, the researcher initiated a study on the effects of watching TV movies, student time management skills on motivational achievement Second, in the Ethiopian context, although there are different types of research studies conducted on different issues in different settings, the researcher did not come across such a study on the effects of Watching TV movies and time management skills on studs. Particularly in primary schools, little research effort has been made on issues related to student motivation for achievement, and even in other schools. It will therefore provide a comprehensive picture of the effects of Watching TV movies and time management skills on student motivation for achievement at this level of schooling.

Third, as the researcher is a member of the school's staff, parents, and students, he noticed a number of school teachers complaining at the TPSA meeting about student motivation, academic activities (doing homework, assignment) and involvement in the classroom. They stated that many students did not do homework, projects, and academic assignments, even when they arrived late in the early morning. Teachers directly attributed the cause of the above problems to late-night Watching and TV shows. 
Thus, the researcher tried to document the issues scientifically by incorporating them into other variables. Therefore, the aim of this study is to investigate the effect of watching TV movies and time management skills on student motivation for achievement.

\section{Method}

This research plan enabled the researcher to numerically study the association amongst the study's dependent and independent variables. Student time management skills and watching TV movies and drama are independent variables whose changes involve dependent variable influences (academic achievement). The present study therefore heads towards a sunshade correlation method.

Three primary schools have been used as data sources, namely Melestegna, Tayitu bitul, and Melka kole, both having a total of $1215(\mathrm{M}=570$ and $\mathrm{F}=645)$ grade 7 and 8 students. Primary sources (students) were the data sources for the study. Data from primary sources was gathered through a questionnaire because it helps many individuals to access a lot of information, besides being easy and economical.

Randomly selected from three primary schools/1,215 students / in Woldia District, Amhara National Regional State, Ethiopia, the study participants were 306 7th and 8th grade students (13-15 years of age). The selection process for the participants is defined as follows. Of the eight public schools located in Woldia City's urban centres, three were selected using a simple random sampling technique, using a lottery system. All schools had 22 grades, with 1,215 in Grade 7 and 8 students in total. The researcher divided the questionnaire into the number of students in each category in all parts.

In this analysis, three distinct questionnaires were used. Mercy C. Ucheom (2011) adapted the first questionnaire, consisting of 10 elements which measured the level of watching TV shows. To determine the level of television viewers, the researcher has prepared an item using Morgan and Shanahan as a reference that shows heavy viewing is more than 3.5 hours per day, medium viewing is between 2.5 hours per day, and light viewing is less than 2.5 hours per day (as cited in Hetsroni, 2008, p. 205).

The questionnaire was organized using the Strongly Disagree (SD), Disagreed (D) Partial Consensus (PA) and Strongly Consensus (SA) Consensus format of the four-item Likert scale. The third questionnaire was used to assess the motivation of the students to accomplish 10 things. The success motivation questionnaire was taken from the motivation scale of achievement of the kifle (2012), adapted from the Deo-Mohan (2001). The questionnaire was structured using the Likert scale format of five items Never, Frequently, Rarel, Always and Sometimes.

As regards the quantitative form of data analysis, mean and standard deviation were used in the study to measure a general comparison. Several linear regressions were used to test the interaction impact of Watching TV movies and time management skills of students on motivation for achievement. In a multi-regression analysis, the independent variables are Watching TV shows and Student Time Management skills. Adequate variable is achievement incentive. To assess the multiple impact of independent variables (Watching TV movies and time management skills) stepwise multiple regression was used. Correlation (Pearson's product moment co-efficient) was used to determine the relationship between Watching TV movies, time management skills, and achievement motivation.

\section{Results and Discussion}

\section{Results}

The primary objective of this part is to pursue an appropriate response to the basic questions posed at the beginning of this research. All questionnaires were provided to 306 primary school respondents and the proportion of returning students was 146 (47.7 per cent) male, 160 (52.28 per cent) female.

\section{Results and analysis of the dependent and independent variables}

Respondents were asked to rate on watching TV films, achievement motivation, and time management skill using two type of a five point likert scale represented by: (never - always continuum). Never $=0$, rarely $=1$, sometimes $=2$, frequently $=3$, and always $=4$; and the other type (agree- disagree continuum) strongly disagree $=1$, disagree $=2$, partially agree $=3$, agree $=4$, and strongly agree $=5$. 
Table 1. Means and Standard Deviations of the Variables Treated in the Study

\begin{tabular}{|c|c|c|c|c|c|c|}
\hline \multirow{3}{*}{ Variables } & \multicolumn{6}{|c|}{ Level of TV viewers } \\
\hline & \multicolumn{2}{|c|}{ High viewers } & \multicolumn{2}{|c|}{ Medium Viewers } & \multicolumn{2}{|c|}{ Low viewers } \\
\hline & Mean & SD & Mean & SD & Mean & SD \\
\hline Achievement motivation & 2.45 & .404 & 2.70 & .187 & 3.61 & .622 \\
\hline Time management skills & 2.44 & .409 & 2.80 & .267 & 3.20 & .396 \\
\hline Watching TV Films & 3.92 & .655 & 2.69 & .172 & 2.53 & .550 \\
\hline
\end{tabular}

As shown in Table 1, high-profile audiences with time management skills have the lowest mean score, i.e. 2.44 relative to accomplishment motivation, and watch TV movies with a mean score of 2.45 and 3.92 respectively. High-level audiences with Watching TV movies have the highest average score; 3.92 compared to achievement motivation and time management skills.

As shown in Table 1, medium-sized viewers watching TV movies have the lowest average score, i.e. 2.69 compared to achievement motivation and time management skills with a mean score of 2.7 and 2.8 respectively. Medium TV Viewers with time management skills have the highest average score; 2.8 compared to others.

Table 1 shows, low TV viewers watching TV movies have the lowest average score, i.e. 2.53 compared to achievement motivation and time management skills with a mean score of 3.61 and 3.20 respectively. Low TV viewers with performance motivation and time management skills have the highest average score; 3.61 and 3.20 compared to Watching TV movies.

Researches question no one is to what extent students are Viewing TV films

So as to answer this question, the responses of the students on the variables were analyzed using frequency and percentage and shown by the following Figure 1 .

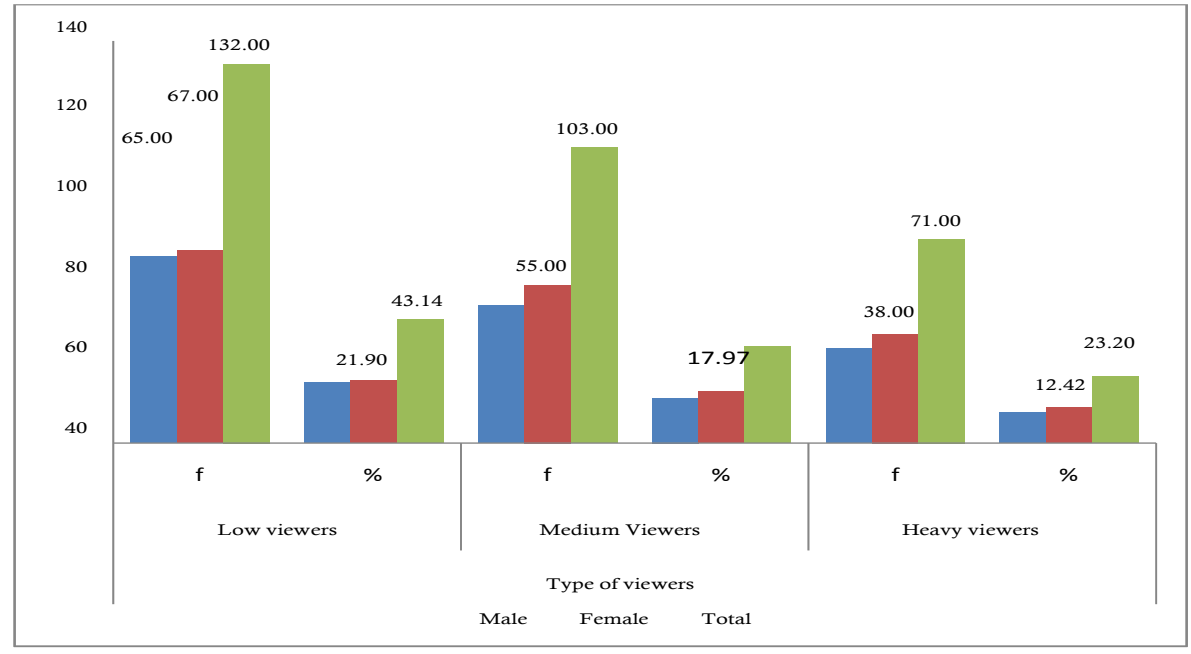

Figure 1. Frequency and Percentage of TV Viewers

Researches question no two. Is there inter- relationship among Watching TV films and Time management skills and achievement motivation of students?

As noted in the description of the issue, one of the goals of this research was the study of Watching TV films, Time management skills and student motivation. To do this, the Pearson product timing correlation has been developed and the results are shown in Table 2. 
Table 2. Correlation Among Watching TV Films, Time Management Skills and Achievement Motivation of Low TV Viewers

\begin{tabular}{llllll}
\hline Variables & Mean & SD & \multicolumn{3}{c}{ Pearson Correlation coefficients } \\
\cline { 3 - 6 } & & & 1 & 2 & 3 \\
1.Achievement motivation & 3.6160 & .62201 & 1 & & \\
2.Time management skills & 3.2000 & .39614 & .121 & 1 & \\
\hline 3.Watching TV Films & 2.5359 & .55067 & .124 & -.144 & 1 \\
\hline
\end{tabular}

$N=132{ }^{* *}$ Correlation is significant at the 0.05 level.

As shown in Table 2 above, the results of the Pearson correlation showed that there was not a significant positive correlation between achievement motivation and time management $(\mathrm{r}(132)=0.121, \mathrm{p}$ $>0.05$ ). In addition, achievement Motivation did not have a significant correlation with Watching TV movies ( $\mathrm{r}(132)=-0.124, \mathrm{p}>0.05)$. Similarly, watching TV movies had no significant correlation with time management skills $(\mathrm{r}(132)=-0.144, \mathrm{p}>0.05)$.

Table 3. The Correlation Watching TV films, Time management skills and achievement motivation of Medium TV viewers

\begin{tabular}{llllll}
\hline Variables & Mean & $S D$ & \multicolumn{3}{c}{ Pearson Correlation coefficients } \\
\cline { 4 - 6 } & & & 1 & 2 & 3 \\
1.Achievement motivation & 2.7058 & .18778 & 1 & & \\
2.Time management skills & 2.8029 & .26769 & $.242^{*}$ & 1 & \\
\hline 3.Watching TV Films & 2.6990 & .17292 & $-.235^{*}$ & $-.220^{* *}$ & 1 \\
\hline
\end{tabular}

$\mathrm{N}=103 *$ Correlation is significant at the 0.01 level.

As shown in Table 3 above, the findings of the Pearson test showed that there was a significant positive association between achievement motivation and time management $\left(\mathrm{r}(103)=0.242^{*}, \mathrm{p}<0.01\right)$. In addition, accomplishment Motivation had a significant negative association with Watching TV movies ( $\mathrm{r}$ $\left.(132)=-0.235^{*}, p<0.01\right)$. Likewise, watching TV movies had a significant negative association with time management skills $\left(\mathrm{r}(132)=-0.220^{* *}, \mathrm{p}<0.01\right)$.

Table 4. The Correlation Watching TV films, Time Management Skills and Achievement Motivation of Heavy TV Viewers

\begin{tabular}{lccccc}
\hline Variables & Mean & SD & \multicolumn{3}{c}{ Pearson Correlation coefficients } \\
\cline { 4 - 6 } & & & 1 & 2 & 3 \\
\hline 1.Achievement motivation & 2.45 & .404 & 1 & & \\
\hline 2.Time management skills & 2.44 & .409 & $.357^{* *}$ & 1 & \\
\hline 3.Watching TV Films & $\mathbf{3 . 9 2}$ & $\mathbf{. 6 5 5}$ & $\mathbf{- . 1 3 7}$ & $\mathbf{- . 2 6 3 ^ { * * }}$ & $\mathbf{1}$ \\
\hline
\end{tabular}

$\mathrm{N}=71 * *$ Correlation is significant at the 0.05 level.

As shown in Table 4 above, the findings of Pearson's correlation showed that there was a significant positive association between achievement motivation and time management of heavy TV viewers $\left(\mathrm{r}(71)=0.357^{* *}, \mathrm{p}<0.05\right)$. In addition, accomplishment Motivation had no significant correlation with Watching TV movies $(\mathrm{r}(71)=-0.137, \mathrm{p}<0.05)$. Furthermore, watching TV films had a significant negative association with the time management skills of heavy TV viewers $\left(r(71)=-0.263^{* *}, p<0.05\right)$.

Research question number 3.

DO students watch TV movies and time management skills individually and/or collectively lead to a significant change in motivational achievement? In order to answer this question, the students ' responses to variables were analyzed using multiple linear regressions. 
Table 5. Results of Regression of Low TV Viewers Achievement Motivation on the Independent Variables

\begin{tabular}{llllll}
\hline & Df & $\begin{array}{l}\text { Sum of } \\
\text { Squares }\end{array}$ & Mean Square & F & Sig. \\
\hline Regression & 2 & 1.782 & .891 & 2.351 & .099 \\
\hline Residual & 129 & 48.891 & .379 & & \\
\hline Total & 131 & 50.673 & & &
\end{tabular}

Multiple $\mathrm{R}=. .188 \mathrm{a} \mathrm{R}$ square $=.035$ Adjusted $\mathrm{R}$ square $=.020$

Analysis of variance

Table 5 Shows that the effect of the combined independent variable is not significant (F2, $129=2,351, \mathrm{P} \geq 0,05)$. The coefficient of determination $(\mathrm{R} 2=.0 .035)$ shows that $3.5 \%$ of the variance in achievement motivation is not explained by the combined effect of independent variables.

Table 6. Regressions Weight of the Independent Variables

\begin{tabular}{|c|c|c|c|c|c|}
\hline \multirow[t]{2}{*}{ Model } & \multicolumn{2}{|c|}{ Unstandardized Coefficients } & \multirow{2}{*}{$\begin{array}{c}\text { Standardized } \\
\text { Coefficients/ } \\
\text { Beta }\end{array}$} & \multirow[t]{2}{*}{$\mathbf{t}$} & \multirow[t]{2}{*}{ Sig. } \\
\hline & B & Std. Error & & & \\
\hline 1 (Constant) & 2.48 & 0.541 & & 4.59 & 0 \\
\hline TMS & 0.22 & 0.138 & 0.142 & 1.62 & 0.11 \\
\hline WT & 0.16 & 0.099 & 0.145 & 1.66 & 0.1 \\
\hline
\end{tabular}

When achievement motivation was reduced for all independent variables, the multiple correlation coefficient was $\mathrm{R}=0.188$ and the coefficient of determination was $\mathrm{R} 2=0.035$. Multiple correlations (Ry. 123) show a significant relationship between low viewer students (y) and the combination of independent variables $(\mathrm{F} 2,129=2.351, \mathrm{P}<0.05)$. Table 6 shows that, among the independent variables, both Watching TV and Time Management skills have no significant impact on the motivation of achievement.

Table 7. Results of regression of medium TV viewers' achievement motivation on the independent variables

\begin{tabular}{|c|c|c|c|c|c|c|}
\hline & Df & $\begin{array}{l}\text { sum } \\
\text { squares }\end{array}$ & of & $\begin{array}{l}\text { mean } \\
\text { square }\end{array}$ & $\mathbf{F}$ & sig. \\
\hline Regression & 2 & .412 & & .206 & 6.53 & $.002^{b}$ \\
\hline Residual & 100 & 3.188 & & .032 & & \\
\hline
\end{tabular}

Although achievement motivation was reduced for all independent variables, the multiple correlation coefficient was $\mathrm{R}=0.115$ and the coefficient of commitment was $\mathrm{R} 2=0.115$. Multiple correlations (Ry. 123) show a significant association between medium TV viewers (y) and the combination of independent variables $(\mathrm{F} 2,100=6.53 \mathrm{p}<0.05)$. The coefficient of determination $(\mathrm{R} 2 \mathrm{y} .123)$ indicates that the linear combination of independent variables accounted for 11,5 per cent of the variation in the motivation of achievement.

Table 7 reveals that, among the independent variables, both Watching TV movies and Time Management skills have a significant impact on the encouragement of achievement . In addition, the direct effect of the variables on the motivation of achievement was calculated using beta coefficients. The impact on academic achievement of time management skills $(\beta=0.206, \mathrm{t}=2.056, \mathrm{P}<0.05)$ and Watching TV movies $(ß=0.210, t=2.116, P<0.05)$ were statistically significant.

The independent contribution of time management skills to the overall variance in academic achievement was found to be 5.665 per cent, which was 58.40 per cent of the total R2 (i.e. 0.097). The independent contribution of watching TV films to the overall variance of achievement encouragement was found to be 5.838 per cent, or 60.1 per cent of the total R2 (0.097). 
Table 8. Results of Regression of Heavy TV Viewers' Achievement Motivation on the Independent Variables

\begin{tabular}{|c|c|c|c|c|c|c|}
\hline & Df & $\begin{array}{l}\text { sum } \\
\text { squares }\end{array}$ & of & $\begin{array}{l}\text { mean } \\
\text { square }\end{array}$ & $\mathbf{F}$ & sig. \\
\hline Regression & 2 & 2.157 & & 1.078 & 7.883 & $.001^{\mathrm{b}}$ \\
\hline Residual & 69 & 9.440 & & .137 & & \\
\hline
\end{tabular}

Multiple $\mathrm{R}=.431 \mathrm{a} \mathrm{R}$ square $=.186$ Adjusted $\mathrm{R}$ square $=.162$

Analysis of variance

Table 8 shows that the effect of the independent variable combined is significant $(\mathrm{F} 2,69=7.883$, $\mathrm{P}<0.05)$. The coefficient of determination $(\mathrm{R} 2=.186)$ shows that $18.6 \%$ of the variance in achievement motivation is explained by the combined effect of the independent variables.

Table 9. Regressions Weight of the Independent Variables

\begin{tabular}{|c|c|c|c|c|c|c|}
\hline \multirow[b]{2}{*}{ Model } & & \multicolumn{2}{|c|}{ Unstandardized Coefficients } & \multirow{2}{*}{$\begin{array}{l}\text { Standardized } \\
\text { Coefficients } \\
\text { Beta }\end{array}$} & \multirow[b]{2}{*}{$\mathbf{t}$} & \multirow[b]{2}{*}{ Sig. } \\
\hline & & B & Std. Error & & & \\
\hline 1 & (Constant) & 4.090 & .435 & & 9.405 & .000 \\
\hline & TMS & -.417 & .111 & -.422 & -3.747 & .000 \\
\hline & WT & -.156 & .069 & -.254 & -2.253 & .027 \\
\hline
\end{tabular}

If achievement motivation was decreased for all independent variables, the multiple correlation coefficient was $\mathrm{R}=0.431$ and the coefficient of commitment was $\mathrm{R} 2=0.186$. Multiple correlations (Ry. 123) show a significant association between heavy TV viewers (y) and the combination of independent variables $(\mathrm{F} 2,69=7.883 \mathrm{p}<0.05)$. The coefficient of determination $(\mathrm{R} 2 \mathrm{y} .123)$ indicates that the linear combination of independent variables accounted for 18.6 percent of the variation in the motivation of achievement. Table 9 reveals that among the independent variables, both Watching TV movies and Time Management skills have a significant impact on the encouragement of achievement.

In addition, the direct effects of the variables on the motivation of achievement were calculated using beta coefficients. The impact on academic achievement of time management skills $(\beta=0 .-357$, $\mathrm{t}=3.747, \mathrm{P}<0.05)$ and Watching TV movies $(\beta=0.137, \mathrm{t}=-2.253, \mathrm{P}<0.05)$ were statistically significant.

The independent contribution of time management skills to the overall variation in academic achievement was found to be 15,654 per cent, which was 96.62 per cent of the total R2 (i.e. 0.162). The independent contribution of watching TV films to the overall variance of achievement motivation was found to be 3,5346 per cent, or 21,81 per cent of the total R2 $(0,162)$.

In this study, the results achieved, i.e. Figure 1 showed that 132 (43.13\%) students were viewers of low TV films (see below 2.5 hours per day), 103 (33.66\%) were viewers of medium TV films (see between 2.5 and 3.5 hours per day) and $71(23.20 \%)$ were viewers of heavy TV films (see above 3.5 hours per day). A survey in the United Kingdom (UK) in 2015 revealed the average number of hours spent watching television, in line with this research. During the survey, 18 per cent of respondents said they watched TV between 6 and 10 hours a week. Similarly, typical American views on average are just over 5 hours of television every single day, most of which are live. About 30 minutes of that time is spent watching previously-filmed shows.

The Pearson Test findings (Table 2) revealed that there was no significant positive association between Watching TV films and time management with student achievement motivation $(r(132)=0.121$, $\mathrm{p}>0.05)$ and $(\mathrm{r}(132)=.124, \mathrm{p}>0.05$ in low TV audiences, respectively.

However, from Table 3 there was a significant positive correlation between time management skills and student achievement motivation in medium TV Film viewers $(\mathrm{r}(103)=0.242, \mathrm{p}<0.05)$, But there was 
a significant negative association between watching TV films and student achievement encouragement in broadcast TV viewers $(\mathrm{r}(103)=-0.235, \mathrm{p}<0.05)$.

In addition to the above results, Table 4 results showed that there was a significant positive association for heavy TV viewers between achievement motivation and time management $\left(\mathrm{r}(71)=0.357^{* *}\right.$, $\mathrm{p}<0.05)$. Additionally, Motivation for success had no significant correlation with Watching TV movies $(r(71)=-0.137, p<0.05)$. Likewise, watching TV films had a significant negative association with heavy TV viewers ' time-management skills $\left(\mathrm{r}(71)=-0.263^{* *}, \mathrm{p}<0.05\right)$.

Similarly, research by Gaddy (1986), Hancox et al. (2005), Mielke (1994), Potter (1987), and Ridley-Johnson et al. (1983) showed that total television time spent by a student is just one of several factors that can make a difference.

Otherwise, spend time on homework assignments, reading, engaging in creative play, or relaxing actually. Potter's (1987) reported that the more television the student watched, the greater the impact this would have on their academic performance.

Additionally, Ridder (1963) questioned seventh and eighth graders about their views on television viewing and found that 75 percent of students felt that watching television was beneficial to their studies, while 20 percent of students suggested that watching television restricted their outdoor time. Another study by Natifia Mullings (August 2012) found that the relationship between time management and academic background is a medium direct positive.

Moreover, there is a strong and substantive relationship between the time management sklls and the students ' academic achievement $[r=, 221 \mathrm{p}<.01]$ Cemaloğ lu, Nve Filiz, S. (2010). If children are overexposed to home videos, their feelings, emotions and curiosity are always directed at such films and this will definitely affect their concentration levels (Arulogun 2009 and Adesanya2004).

Specific associations i.e. Table 5 (Ry. 123) suggests a significant relationship between low-viewers (y) students and the combination of independent variables ( F2, 129=2,351, P<0.05). The determination coefficient (R2y. 123) shows that 3.5 percent of the variance in the achievement motivation was registered. Table 6 reveals that both Watching TV and Time Management skills have no significant impact on encouraging achievement among the independent variables.

Multiple correlations (Table 7) (Ry. 123) show a significant association between medium TV viewers (y) and an independent variables combination ( F 2, 100=6.53 p<0.05). The determination coefficient (R2y. 123) indicates that the linear combination of independent variables represented 11.5 per cent of the variation in achievement motivation.

Table 7 indicated that both Watching TV films and Time Management skills had a significant impact on the motivation of achievement among the independent variables. In addition, the direct effect of the variables on the motivation of achievement was determined using beta coefficients. The effect of time management skills $(\beta=0.206, t=2.056, P<0.05)$ and Watching TV movies $(\beta=0.210, t=2.116, P<0.05)$ on academic achievement was statistically significant.

It was found that the independent contribution of time management skills to the overall variance in academic achievement was 5,665 per cent, which was 58.40 per cent of total R2 (i.e. 0.097). The independent contribution of watching TV films to the overall variance of the achievement incentive was found to be $5.838 \%$, or $60.1 \%$ of the total R2 (0.097).

Multiple correlations (Table 8) (Ry.123) show a significant relationship between heavy TV viewers (y) and the combination of independent variables (F 2, 69=7,883 $p<0,05)$. The coefficient of determination (R2y. 123) shows that the linear combination of independent variables accounted for 18.6 percent of the variability in the motivation of achievement.

Table 9 indicated that, among the independent variables, both Watching TV movies and Time Management skills had a significant effect on the motivation of achievement In addition, the direct effects of the variables on the motivation of achievement were determined using beta coefficients. The effects on academic achievement of time management skills $(\beta=0 .-357, t=3.747, \mathrm{P}<0.05)$ and Watching TV movies $(ß=0.137, \mathrm{t}=-2.253, \mathrm{P}<0.05)$ were statistically significant. The independent contribution of time management skills to the overall variance in academic achievement was found to be 15,654 per cent, 
which was 96.62 per cent of the total R2 (i.e. 0.162). The independent contribution of watching TV films to the total variance of achievement motivation was found to be 3,5346 per cent, or 21,81 per cent of the total R2 $(0,162)$.

\section{Conclusions}

Accordingly, it is possible to arrive at the following conclusions from the findings that Children have been highly subject to Watching TV movies and drama, and this has had a major impact on their motivation for achievement. So, they weren't so motivated to do assignments, homework, and other related tasks. Also Viewing TV movies and drama, and student management skills have had a significant relationship with their motivation for achievement. It was concluded from the findings that there was a negative relationship between watching TV movies and acting, and student motivation for achievement.

The following recommendations were made on the basis of the findings of this study. The recomendation are 1) Families will limit their children to seeing only programming that can lead to better changes in their lives and their time spent on television, so that their children will become successful people who benefit their communities and the world. 2) Parents must always exercise discipline and force their children to watch excessive television so that their academic performance is not negatively affected. 3) To reduce the amount of time spent watching TV. 4) teachers should have ample assignment to occupy students during their leisure time. Parents are well aware that media can impact the performance of their children.

\section{References}

Alay, S., \& Koçak, S. (2003). Relationship between time management and academic achievement of university students. Kuram ve Uygulamada Eğitim Yönetimi Dergisi, 35, 326-335.

Anderson, D.R. Huston, A.C., Schmitt, K., Linebarger, D.L., Wright, J.C. (2001). Earlychildhood television viewing and adolescent behaviour: The reconstruct study.Monographs of the Society for Research on Child Development, 66(264).

Armstrong, G.B., Boirsky, G.A. \& Mares, M.L. (1991). Background television and reading performance.Communications Monograph, 58.

Atusenuwa. K. (2002). Human resources management: Lecture Note. Ambrose Ali University, Ekpoma Awake (July 22). New York:Watcht ower Bible and Tract Society Inc.

Brigitte, J. C., Claessens, Eerde, W. V., Rutte, C. G, Roe, R. A. (2005). A review of the time management literature. Emerald Group Publishing Limited, 36 (2), 2007.

Britton, B. K., \& Tesser, A. (2001). Effects of time management practices on college grades. Journal of Educational Psychology, 83, 405-410

Canadian Paedriatic Society (CPS). Effects of the television on children. Retrieved 19

Denlinger, J. C. (2009). The Effects of Time Management on College Students' Academic Performance, Ball State University, Fact Book (students/enrollment).

Dimkpa, D.I. (2006). Factors associated with indecent dressing among female studentsof tertiary institutions in Nigeria. Journal of Education in Developing Areas (JEDA),15(2), 157- 164.

Dowson, M., \& McInerney, D. M. (2001). Psychological parameters of students' social and work avoidance goals: A qualitative investigation. Journal of Educational

Faisal, Z., Miqdadi, A. F., Mohammad, T., \& Nabil, M. (2014). The Relationship between Time Management and the Academic Performance of Students. University of Bridgeport, Bridgpeort, CT, USA

Fazal, S. (2012), The Role of Study Skills in Academic Achievement of Students: A Closer Focus on Gender. Pakistan journal of Psychological research, 27 (1), p- 37-51.

Felter E. (2004). Television and Your Child: A Guide for Concerned Parents. Toronto: TV Antario

Ferri, Z.O. (2009). Television and Academic Achievement. Indonesian Journal of Language and Communication, 6 (2) $332-336$.

Forley, J. (2000).Ethics in communication.Africa: Paulines Publications

Gaddy, D. (1986). Television'seffect on high school achievement. Public Opinion Quarterly,50(3), 340-359

Gentile, D. A., \& Walsh, D. A. (2002). A normative study of family media habits. Journal of Applied Developmental Psychology, 23, 157-178. 
Gentile, D.A. \& Walsh, D. A. (2002, January). A normative study of family media habits.Applied Developmental Psychology, 23, 157-178.

Hancox, R., Milne, B., \& Poulton, R. (2005). Association of television viewing during childhood with poor educational achievement. Archives of Pediatrics and Adolescent Medicine, 159(1), 614-618.

Izundu, I. T. (2005). Relationship between Home Environmental factors and academic performance of secondary school students'. Unpublished Ph.D Thesis University of Nigeria, Nsukka.

Karim., \& Mitra, K. (2015), Time management skills effect on self-efficacy and academic performance. Journal of American Science, 7(12).

Kathryn, D. (2010). Academic performance achievement. Retrieved June 14, 2011,from http://www.nichgy.org.

Kaushar, M. (2013). Study of Effect of Time Management on Academic Performance of College Students. Journal of Business and Management, 9 (6), P 59-60.

Keith, (2000). Relationship between school libraries and academic performance in Okigwe Senatorial Zone. Unpublished M. Ed thesis.

Kelly, M. (2004). Get time on your side, Careers \& Universities, 24 (4), p.28.

Laurie, A., \& Hellsten, M. (2002). What Do We Know About Time Management? A Review of theLiterature and a Psychometric Critique of Instruments Assessing Time Management University of Saskatchewan, Canada.

Lisa, M., \& Robert, M. S. (2008). I will do it tomorrow: College Teaching. 57 (5), p.21- 2154.

Academic One-File, https://www.ebscohost.com[Accessed Oct 4, 2011.

Maehr, M. L. (2008). Culture and achievement motivation, International Journal of Psychology, 43: 5, $917-$ 918

McClelland, D. C. (1985). Human motivation. Chicago:Scott Foresman.

McClelland, D.C. (1961). The achieving society. Princeton, New Jersey: Van Nostrand. McClelland, D.C., \& Winter, D.G. (1969). Motivating economic achievement. New York: Free Press

Media Awareness Network. Effect of TV viewing on children. Retrieved.http:// mohnkucheniwritebrief 2 blogspot.com/2009/05/education 03.html.

Mercanlioglu. C. (2010), the Relationship of Time Management to Academic Performance of Master Level Students, International Journal of Business And Management Studies, 2 (1), p. 255-276.

Mielke, K.W. (1984). On the relationship between television viewing and academic achievement. Journal of Broadcasting \& Electronic Media, 38(3), 361-366.Nigerian Journal of Curriculum Studies,

Nneji, L.M. (2004). An impediment to curriculum implementation at the tertiary levelof education. In A.O.K. Noah, D.O. Shonibare, A.A. Ojo, \& Olujuwon (eds.). (Pp.149- 155). Curriculum implementation and professionalizing teaching. Sabo-Yaba, Lagos: C.E.S. Publications.

Noar, S. M., Anderman, E. M., Zimmerman, R. S. \& Cupp, P. K. (2005). Fostering Achievement Motivation in Health Education, Journal of Psychology \& Human Sexuality, 16: 4, 59-76

Noftle, E., Robins., \& Richard, W. (2007). Personality predictors of academic outcomes: Big five correlates of GPA \& SAT scores. Journal of Personality and Social Psychology, 93, 116-130.

Nwafor, N.H.A.(2006).Youth violence in the Niger Delta and its educationalimplications.Journal of Education in developing Areas.

Omojuwa, A., Timothy, C. and Obiekezic, E. (2009). The Television Factors in Vocabulary Development among Secondary School Students in Cross River State, Nigeria. Global Journal of Educational Research, 8 (132): 55 - 59

Raj, P. S. (2012, April 20). Sedentary lifestyle: It's time to unplug and play. New Straits Times, Retrieved June 10, 2013, from http://www.nst.com.my/opinion/letters-to-the- editor/sedentary-lifestyle-it-stime-to-unplug-and-play-1.75817 Reading Research and Instruction,

Reiking, D. \& Wu, J. (1990). Re- examining the research on television and reading.

Ridley-Johnson, R., Cooper, H., \& Chance, J. (1983). The relation of children's television viewing to school achievement and I.Q. The Journal of Educational Research, 76(5), 294-297.

Sabelis, I. (2001), "Time management: paradoxes and patterns". Time \& Society, 10, p- 387-400.

Sevari, K., \& Kandy, M. (2011). Time management skills effect on self-efficacy and academic performance. Journal of American Science, 7(12), 720-726.

Steinberg, L. (2005). Psychology of adolescents. New York: McGraw Hill.

Tina, S. and Melinda, L.S. (2007). The Effect of Television on Time Spent Completing an Assignment. J. Undergraduate Psychal Resources, Pp 2. 
Ucheoma, M.C (2008). Relationship between oral reading miscues and reading comprehension Ph.D Dissertation submitted to the Faculty of Education, AbiaState University.

Yilmaz, I., Yoncalik, O., \& Bektaş, F. (2006). Relationship between the time management behavior and academic success. E-Journal of New World Sciences Academy, 5(3), 187-194. 